\title{
Acúmulo de nutrientes e rendimento de óleo em plantas de girassol influenciados pelo vigor dos aquênios e pela densidade de semeadura
}

\section{Sunflower plants nutrients accumulation and oil yield as affected by achenes vigour and sowing density}

\author{
Madelon Rodrigues Sá Braz ${ }^{1 *}$; Claudia Antônia Vieira Rossetto²
}

\begin{abstract}
Resumo
O objetivo do trabalho foi avaliar o acúmulo de nutrientes e o rendimento de óleo dos aquênios em plantas de girassol produzidas sob a influência do vigor dos aquênios e da densidade de semeadura. Para isto, foi instalado um experimento no campo experimental no município de Seropédica/RJ, em outubro de 2006, com três distintos lotes de aquênios de girassol cv Embrapa 122 V2000, classificados como de baixo, de médio e de alto vigor, sob duas densidades de semeadura (45.000 e 75.000 sementes ha $\left.{ }^{-1}\right)$. Aos 20, 60 e 100 dias após a semeadura (DAS), foram coletadas as plantas para avaliação da massa de matéria seca e do acúmulo de nitrogênio, de fósforo, de potássio e de cálcio, no caule, nas folhas e nos capítulos. Nas plantas coletadas aos 100 DAS, foi feita também a avaliação do rendimento de aquênios $\left(\mathrm{kg} \mathrm{ha}^{-1}\right)$, do teor de óleo e do rendimento de óleo $\left(\mathrm{kg} \mathrm{ha}^{-1}\right)$. Observou-se que aos $60 \mathrm{DAS}$, no período entre o florescimento e o enchimento, ocorreu maior acúmulo de massa de matéria seca e de N, P, K e Ca no caule, nas folhas e total nas plantas de girassol produzidas sob a densidade de 45.000 sementes $\mathrm{ha}^{-1}$. Não houve efeito do vigor dos aquênios e da densidade de semeadura no rendimento de óleo dos aquênios de girassol e nos índices de colheita de aquênios e nutrientes. Houve translocação preferencial de $\mathrm{N}$ e $\mathrm{P}$ para os aquênios.
\end{abstract}

Palavras-chave: Helianthus annuus L, grãos, época de colheita, macronutrientes

\begin{abstract}
The objective this work was to evaluate the nutrients accumulation and achenes oil yield in sunflower plants as affected by achenes vigour and sowing density. An experiment was installed in the field at Seropédica, State of Rio de Janeiro, in October 2006 with three lots of sunflower achenes, cultivar Embrapa 122 V2000, classified as low, medium and high vigour and two sowing density (45,000 e 75,000 seeds.ha ${ }^{-1}$ ). The collected were realized at 20,60 and 100 days after planting (DAP) to the determination the dry mater, nitrogen, phosphorus, potassium and calcium. In the collecting at 100 DAP too it was evaluated the achene yield $\left(\mathrm{kg} \mathrm{ha}^{-1}\right)$, the content oil and oil yield $\left(\mathrm{kg} \mathrm{ha}^{-1}\right)$. The results indicated that to the 60 days high accumulation of dry mater, N, P K and Ca in stem, leaves and total at density of 45,000 seeds ha-1. The sunflower achenes oil yield and achenes and nutrients harvest index not affected by the achenes vigour and sowing density to. There was a preferential translocation of $\mathrm{N}$ and $\mathrm{P}$ for the achenes.
\end{abstract}

Key words: Helianthus annuus L, grain, harvest time, macronutrients

\footnotetext{
${ }^{1}$ Parte da Tese de Doutorado da autora apresentado a UFRRJ. Prof ${ }^{a}$ Adjunta I do Departamento de Engenharia da Universidade Federal Rural do Rio de Janeiro, UFRR Seropédica, RJ; CEP:23.890-000. E-mail: madelonsa@ufrrj.br

${ }^{2}$ Prof ${ }^{a}$ Associada III da Universidade Federal Rural do Rio de Janeiro, UFRRJ do Departamento de Fitotecnia, Seropédica, RJ; CEP:23.890-000. E-mail: cavrosse@ufrrj.br

* Autor para correspondência
} 


\section{Introdução}

O girassol ocupa destaque entre as oleaginosas, sendo considerada a quinta oleaginosa em produção de grãos e a quarta em produção de óleo no mundo (ESTADOS UNIDOS, 2008). O óleo do girassol, presente nos grãos denominados de aquênios, apresenta alta qualidade para o consumo humano, bem como ainda pode ser usado como biodiesel (LAZZAROTTO; ROESSING; MELLO, 2005). Para a cultivar Embrapa 122 V2000, Carvalho et al. (2007) constataram que o rendimento de óleo variou entre $437,6 \mathrm{~kg} \mathrm{ha}^{-1}$ para o estado do Rio Grande do Sul e 1282,0 kg ha ${ }^{-1}$ para o Distrito Federal. Também, Porto et al. (2008) verificaram que o rendimento de óleo, para esta cultivar variou de 598,31 $\mathrm{kg} \mathrm{ha}^{-1}$ a 893,33 $\mathrm{kg} \mathrm{ha}^{-1}$, dependendo das condições ambientais.

Entre os fatores que contribuem para elevada produção da cultura, destaca-se o acúmulo de nutrientes nas plantas. Oliveira et al. (2005) constataram que a quantidade total extraída de macronutrientes na parte aérea para uma produção de $3.176 \mathrm{~kg}$ de aquênios ha-1 foi de $130 \mathrm{~kg} \mathrm{ha}^{-1}$ de $\mathrm{N}, 25 \mathrm{~kg} \mathrm{ha}^{-1}$ de P e $400 \mathrm{~kg} \mathrm{ha}^{-1}$ de K, no período do florescimento. Para o hibrido Hélio 251, Castro e Farias (2005) verificaram que há aumento máximo de acúmulo de nutrientes no período entre 56 e 84 dias após a emergência, que corresponde a fase entre o florescimento e enchimento dos aquênios.

Outro fator que contribui para a alta produção da cultura é o estabelecimento de uma população de plantas adequada e uniformemente distribuída, que depende do vigor dos aquênios (MURCIA et al., 2001). Além disso, de acordo com Mussi (2005), o ciclo de vida da planta pode ser influenciado pelas características fisiológicas dos aquênios e com isso apresentar capacidade diferenciada de acumular matéria seca.

Em relação ao rendimento de óleo, tem sido observado que este é influenciado por vários fatores genéticos e ambientais, dentre estes o arranjo de plantas. Silva e Nepomuceno (1991) verificaram que para a cultivar Contisol 711, quando foi aumentada a densidade de 30.000 para 70.000 plantas ha ${ }^{-1}$, o teor de óleo aumentou de 42 para 45\%. Silva et al. (1995) também trabalhando com a mesma cultivar, constataram que além do teor de óleo aumentar de 38 para $40 \%$, o rendimento de óleo também aumentou de 911 para $1081 \mathrm{~kg} \mathrm{ha}^{-1}$ com a elevação da densidade de plantas de 25.000 para 50.000 plantas ha ${ }^{-1}$.

Diante do exposto, o objetivo do trabalho foi avaliar o acúmulo de nutrientes e o rendimento de óleo dos aquênios em plantas de girassol produzidas sob influência do vigor dos aquênios e da densidade de semeadura.

\section{Material e Métodos}

Oexperimentofoiinstaladoem27/10/2006,nosetor de campo da Bovinocultura de Leite da Universidade Federal Rural do Rio de Janeiro, em Planossolo, cujo resultado da análise química apresentava: $\mathrm{pH}($ água $)=5,5 ; \mathrm{Ca}=3,2 \mathrm{cmol}_{\mathrm{c}} \mathrm{dm}^{-3} ; \mathrm{Mg}=1,7 \mathrm{cmol}_{\mathrm{c}} \mathrm{dm}^{-3}$; $\mathrm{P}=21 \mathrm{mgL}^{-1} ; \quad \mathrm{K}=32 \mathrm{mgL}^{-1} ; \quad \mathrm{H}+\mathrm{Al}=3,0 \mathrm{cmol}_{\mathrm{c}} \mathrm{dm}^{-3} \mathrm{e}$ $\mathrm{V} \%=63$. Três meses antes da semeadura (DAS), foi realizada calagem, visando atingir $70 \%$ de saturação por bases no solo. Na semeadura, foi feita a adubação com $10 \mathrm{~kg} \mathrm{ha}^{-1}$ de $\mathrm{N}$ (sulfato de amônio), com $30 \mathrm{~kg}$ ha $^{-1}$ de $\mathrm{P}_{2} \mathrm{O}_{5}$ (superfosfato simples) e com $50 \mathrm{~kg} \mathrm{ha}^{-1}$ de $\mathrm{K}_{2} \mathrm{O}$ (cloreto de potássio). Aos $30 \mathrm{DAS}$, foi feita a adubação de cobertura com $40 \mathrm{~kg} \mathrm{ha}^{-1}$ de $\mathrm{N}$ (sulfato de amônio) (RAIJ; CANTARELLA; FURLANI, 1997). Durante a condução, também foram coletados os dados médios diários de temperatura média e de umidade relativa (UR) do ar na estação meteorológica da PESAGRO (INMET/PESAGRO-RIO).

O delineamento experimental adotado foi de blocos ao acaso com parcelas subdivididas, com quatro repetições. As parcelas foram representadas por duas densidades de semeadura (45 e 75 mil sementes $\mathrm{ha}^{-1}$ ) e as subparcelas por três lotes de aquênios de girassol cv. Embrapa 122 V2000, previamente classificados como de baixo, médio e alto vigor, com $82,82,87 \%$ de germinação; 
50, 62 e 70\% de plântulas normais no teste de envelhecimento acelerado e 41,34 e $28 \mu \mathrm{S} \mathrm{cm}$ $\mathrm{g}^{-1}$ no teste de condutividade elétrica, designados, respectivamente, de lote 1,2 e 3 . Cada subparcela foi formada por oito linhas de $3,5 \mathrm{~m}$, com espaçamento de $0,7 \mathrm{~m}$.

Aos 20, 60 e 100 dias após a semeadura (DAS), que correspondem, respectivamente, a fase vegetativa (V8 - 8 folhas com pelo menos $4 \mathrm{~cm}$ de comprimento), a fase entre o florescimento e o enchimento das sementes (R5 - $100 \%$ das flores liguladas expandidas e $50 \%$ das flores tubulares em antese) e a fase após a maturação fisiológica (R9) (SCHNEITER; MILLER, 1981), foram realizadas coletas de plantas para análise. Em cada coleta, as plantas foram colhidas em um metro linear e separadas em caule, folhas+pecíolos e capítulo, e colocadas para secar a $60^{\circ} \mathrm{C}$, em estufa, até atingir peso constante, para avaliação da massa seca. Após a secagem, as amostras foram pesadas, moídas e submetidas à digestão, sendo o nitrogênio quantificado pelo método de destilação semi-microKjeldahl, o potássio por fotometria de emissão de chama e o cálcio por fotometria de absorção (TEDESCO, 1995). O fósforo foi quantificado pelo método de colorimetria do metavanadato (MALAVOLTA; VITTI; OLIVEIRA, 1997). Os resultados das análises forneceram as concentrações dos nutrientes (N, P, K e Ca) e para se determinar a quantidade acumulada em cada parte da planta, multiplicou-se a concentração pela massa seca da referida parte. Foi calculado o índice de colheita para cada nutriente, por meio da relação entre o acúmulo do nutriente nos aquênios e o acúmulo de nutrientes total (CASTRO; FARIAS, 2005).

Os capítulos colhidos aos 100 DAS foram debulhados e os aquênios, previamente pesados, foram submetidos à determinação do teor de óleo, por extração com éter sulfúrico, no aparelho Soxhlet (UNGARO et al., 1992). O rendimento de óleo $\left(\mathrm{kg} \mathrm{ha}^{-1}\right)$ foi obtido por cálculo, considerando o teor de óleo nos aquênios e o rendimento dos aquênios $\left(\mathrm{kg} \mathrm{ha}^{-1}\right)$.
Os dados foram inicialmente submetidos aos testes de Lilliefors e de Bartlett, para verificar a normalidade e homogeneidade dos erros (RIBEIRO JÚNIOR, 2001). Somente os dados coletados aos 20 DAS não foram submetidos à transformação de $\log (\mathrm{x})$. Posteriormente, por época de coleta, foi realizada a análise de variância e, em seguida, a avaliação da relação entre o maior e menor quadrado médio do erro, para verificar a possibilidade da análise conjunta dos dados (BANZATTO; KRONKA, 2006). No entanto, com base nos resultados não foi realizada a análise conjunta. As médias foram comparadas pelo teste Tukey, a 5\% de probabilidade. Nas tabelas encontram-se os dados originais.

\section{Resultados e Discussão}

Aos 20 dias após a semeadura (DAS), não foi constatada diferença significativa entre as densidades de semeadura e entre lotes de aquênios para massa de matéria seca de caule, folhas e total (Tabela 1). No entanto, foi constatado, aos 60 DAS, na fase de florescimento, maior acúmulo de massa de matéria seca na parte aérea das plantas de girassol, sob a densidade de 45.000 sementes ha $^{-1}$, independente do nível de vigor dos aquênios, apresentando valor médio de $4944 \mathrm{~kg} \mathrm{ha}^{-1}$, com partição de $2561 \mathrm{~kg}$ $\mathrm{ha}^{-1}(51,80 \%)$ do caule, de $1604 \mathrm{~kg} \mathrm{ha}^{-1}(32,44 \%)$ das folhas e de $778 \mathrm{~kg} \mathrm{ha}^{-1}(15,74 \%)$ dos capítulos (Tabela 1). No entanto, Oliveira et al. (2005) relataram que na fase de florescimento a produção de matéria seca total no girassol hibrido 251 foi de $8000 \mathrm{~kg} \mathrm{ha}^{-1}$. De acordo com Castro e Farias (2005), o acúmulo de matéria seca está relacionado às características fenotípicas e ambientais. Assim, estes resultados podem ser devido à ausência de precipitação pluvial e de temperatura máxima de $36^{\circ} \mathrm{C}$ (dados não apresentados) no período entre $52 \mathrm{e}$ 56 DAS. Essa condição é considerada desfavorável para o girassol (COX; JOLLIFF, 1986) e, com isso, pode ter prejudicado o acúmulo máximo de matéria seca por parte das plantas. 
Tabela 1. Dados médios de massa de matéria seca de caule, folhas, capítulo, aquênios e total, e de índice de colheita dos aquênios, obtidos de plantas de girassol colhidas aos 20, 60 e 100 DAS, provenientes de lotes de aquênios com distintos níveis de vigor, designados de lote 1, 2 e 3, sob 45.000 e 75.000 sementes ha-1.

\begin{tabular}{|c|c|c|c|c|c|c|c|c|c|}
\hline \multirow[b]{2}{*}{ Lotes } & \multicolumn{3}{|c|}{20} & \multicolumn{3}{|c|}{60} & \multicolumn{3}{|c|}{100} \\
\hline & 45.000 & 75.000 & médias & 45.000 & 75.000 & médias & 45.000 & 75.000 & médias \\
\hline & \multicolumn{9}{|c|}{ Caule $\left(\mathrm{kg} \mathrm{ha}^{-1}\right)$} \\
\hline 1 & 5 & 6 & $5 a$ & 1717 & 1123 & $1420 \mathrm{a}$ & 1181 & 1182 & $1181 \mathrm{a}$ \\
\hline 2 & 4 & 6 & $5 a$ & 3511 & 2148 & $2829 \mathrm{a}$ & 1395 & 786 & $1090 \mathrm{a}$ \\
\hline 3 & 5 & 5 & $5 \mathrm{a}$ & 2456 & 1777 & $2116 a$ & 1085 & 1164 & $1124 \mathrm{a}$ \\
\hline Médias & $5 \mathrm{~A}$ & $6 \mathrm{~A}$ & & $2561 \mathrm{~A}$ & 1683B & & $1220 \mathrm{~A}$ & $1044 \mathrm{~A}$ & \\
\hline C.V.(\%) parcela & & 31,09 & & 5,11 & & & 7,02 & & \\
\hline \multirow[t]{2}{*}{ C.V.(\%) subparcela } & & 32,10 & & 13,36 & & & 9,63 & & \\
\hline & \multicolumn{9}{|c|}{ Folhas $\left(\mathrm{kg} \mathrm{ha}^{-1}\right)$} \\
\hline 1 & 14 & 15 & $14 \mathrm{a}$ & 1477 & 964 & $1220 \mathrm{a}$ & 246 & 181 & $213 a$ \\
\hline 2 & 15 & 17 & $16 \mathrm{a}$ & 1651 & 1312 & $1481 \mathrm{a}$ & 222 & 208 & $215 a$ \\
\hline 3 & 17 & 18 & $17 \mathrm{a}$ & 1683 & 1388 & $1535 \mathrm{a}$ & 156 & 210 & $183 a$ \\
\hline Médias & $15 \mathrm{~A}$ & $17 \mathrm{~A}$ & & $1604 \mathrm{~A}$ & $1221 \mathrm{~B}$ & & $208 \mathrm{~A}$ & $200 \mathrm{~A}$ & \\
\hline C.V.(\%) parcela & & 39,15 & & 6,39 & & & 9,67 & & \\
\hline \multirow[t]{2}{*}{ C.V.(\%) subparcela } & & 30,48 & & 9,74 & & & 27,58 & & \\
\hline & \multicolumn{9}{|c|}{ Capítulo $\left(\mathrm{kg} \mathrm{ha}^{-1}\right)$} \\
\hline 1 & - & - & - & 722 & 399 & $560 \mathrm{a}$ & 723 & 637 & $680 \mathrm{a}$ \\
\hline 2 & - & - & - & 756 & 534 & $645 \mathrm{a}$ & 753 & 550 & $651 \mathrm{a}$ \\
\hline 3 & - & - & - & 857 & 539 & $698 \mathrm{a}$ & 637 & 589 & $613 a$ \\
\hline Médias & - & - & - & $778 \mathrm{~A}$ & 491B & & $704 \mathrm{~A}$ & $592 \mathrm{~A}$ & \\
\hline C.V.(\%) parcela & & & & 15,11 & & & 5,98 & & \\
\hline \multirow[t]{2}{*}{ C.V.(\%) subparcela } & & & & 10,35 & & & 7,69 & & \\
\hline & \multicolumn{9}{|c|}{ Aquênios $\left(\mathrm{kg} \mathrm{ha}^{-1}\right)$} \\
\hline 1 & - & - & - & - & - & - & 1149 & 1165 & $1157 \mathrm{a}$ \\
\hline 2 & - & - & - & - & - & - & 1635 & 1064 & $1349 a$ \\
\hline 3 & - & - & - & - & - & - & 1474 & 1073 & $1273 a$ \\
\hline Médias & - & - & - & - & - & - & 1419A & $1101 \mathrm{~A}$ & \\
\hline C.V.(\%) parcela & & & & & & & 8,41 & & \\
\hline \multirow[t]{2}{*}{ C.V.(\%) subparcela } & & & & & & & 10,41 & & \\
\hline & \multicolumn{9}{|c|}{ Total $\left(\mathrm{kg} \mathrm{ha}^{-1}\right)$} \\
\hline 1 & 19 & 21 & $20 \mathrm{a}$ & 3916 & 2485 & $3200 \mathrm{a}$ & 3299 & 3165 & $3232 \mathrm{a}$ \\
\hline 2 & 19 & 23 & $21 \mathrm{a}$ & 5918 & 3994 & $4956 a$ & 4005 & 2608 & $3306 a$ \\
\hline 3 & 21 & 22 & $21 \mathrm{a}$ & 4997 & 3704 & $4350 \mathrm{a}$ & 3352 & 3037 & $3277 \mathrm{a}$ \\
\hline Médias & $20 \mathrm{~A}$ & $22 \mathrm{~A}$ & & $4944 \mathrm{~A}$ & 3394B & & $3551 \mathrm{~A}$ & 2937A & \\
\hline C.V.(\%) parcela & & 34,03 & & 5,28 & & & 5,32 & & \\
\hline \multirow[t]{2}{*}{ C.V.(\%) subparcela } & & 35,85 & & 9,45 & & & 6,38 & & \\
\hline & \multicolumn{9}{|c|}{ IC } \\
\hline 1 & - & - & - & - & - & - & 0,34 & 0,36 & $0,35 \mathrm{a}$ \\
\hline 2 & - & - & - & - & - & - & 0,40 & 0,41 & $0,40 \mathrm{a}$ \\
\hline 3 & - & - & - & - & - & - & 0,44 & 0,35 & $0,40 \mathrm{a}$ \\
\hline Médias & - & - & - & - & - & - & $0,40 \mathrm{~A}$ & $0,37 \mathrm{~A}$ & \\
\hline C.V.(\%) parcela & & & & & & & 3,63 & & \\
\hline C.V.(\%) subparcela & & & & & & & 10,12 & & \\
\hline
\end{tabular}

Médias seguidas pela mesma letra, maiúscula na linha e minúscula na coluna, não diferem entre si pelo teste Tukey, a 5\%. 
Já para massa de matéria seca de caule, folhas, capítulos e de aquênios, aos 100 DAS, não foi constatada diferença entre tratamentos (Tabela 1). Rizzardi e Silva (1992) constataram que a massa de matéria seca nos aquênios diminuiu com o aumento da densidade de semeadura de 10.000 para 50.000 sementes $\mathrm{ha}^{-1}$, indicando que a cultivar Contisol 711 mostrou-se sensível ao aumento da competição intraespecífica. Observou-se que para índice de colheita não foi constatada diferença entre os tratamentos (Tabela 1). Cox e Jolliff (1986) também não verificaram diferença no índice de colheita de plantas de girassol, mesmo quando apresentaram diferenças na produção de massa de matéria seca em condição de restrição hídrica no solo.

Aos 20 DAS, para acúmulo de $\mathrm{N}$ no caule, nas folhas e total, não foi constatada diferença significativa entre as densidades de semeadura e entre lotes de aquênios (Tabela 2). No entanto, aos 60 DAS, o maior acúmulo de $\mathrm{N}$ no caule, folhas e total, foi observado sob 45.000 sementes $\mathrm{ha}^{-1}$, independente do lote de aquênios (Tabela 2). Neste período, a média do acúmulo total foi de $127 \mathrm{~kg}$ ha1, com partição de $43 \mathrm{~kg} \mathrm{ha}^{-1}(33,85 \%)$ do caule e $64 \mathrm{~kg} \mathrm{ha}^{-1}(50,39 \%)$ das folhas, coincidindo com a época de maior acúmulo de massa de matéria seca da parte aérea das plantas (Tabela 1). Esses resultados foram semelhantes ao observado por Castro e Oliveira (2005), que verificaram que o acúmulo de nitrogênio em plantas de girassol do hibrido 251 foi em torno de $130 \mathrm{~kg} \mathrm{ha}^{-1}$, também aos 60 DAS. Para o índice de colheita de nitrogênio não foi constatada diferença entre as densidades de semeadura e entre lotes de aquênios (Tabela 2). O mesmo foi verificado aos 100 DAS para teor de nitrogênio no caule, nas folhas, no capítulo, nos aquênios, total e índice de colheita de nitrogênio (Tabela 2).

Para acúmulo de P no caule, nas folhas e total aos 20 DAS, não foi constatada diferença significativa entre as densidades de semeadura e entre lotes de aquênios (Tabela 3). No entanto,aos 60 DAS, para o acúmulo de $\mathrm{P}$ no caule, nas folhas e total, os maiores valores foram observados sob 45.000 sementes $\mathrm{ha}^{-1}$, independente do lote de aquênios (Tabela 3). No entanto, aos 100 DAS, não houve diferença entre tratamentos. De acordo com Sfredo, Campo e Sarruge (1984), para a cultivar Contisol, após a floração, a absorção de P pelas folhas e caule é menor, já que este é translocado para os capítulos e aquênios. Também para o índice de colheita de fósforo não foi constatada diferença entre os tratamentos (Tabela 3).

Pela (Tabela 4), foi constatado aos 20 DAS, que não houve diferença significativa entre as densidades de semeadura e entre lotes de aquênios para acúmulo de K no caule, nas folhas e total. Já aos 60 DAS, para o acúmulo de $\mathrm{K}$, no caule, nas folhas e total, o maior valor foi obtido sob a menor densidade de semeadura (45.000 sementes ha ${ }^{-1}$ ), atingindo um total de $149 \mathrm{~kg} \mathrm{ha}^{-1}$ (Tabela 4). Segundo Castro e Oliveira (2005), a concentração de potássio na parte aérea, no período do florescimento, deve estar próxima de $427 \mathrm{~kg} \mathrm{ha}^{-1}$. Assim, o resultado encontrado no experimento é considerado baixo e pode estar relacionado ao baixo acúmulo de massa de matéria seca no período (Tabela 1). Além disso, não foi constatada diferença significativa entre os tratamentos para capítulos, aquênios e para índice de colheita, em todas as épocas de coleta (Tabela 4). 
Tabela 2. Dados médios de acúmulo de nitrogênio no caule, nas folhas, no capítulo, nos aquênios e total, e de índice de colheita dos aquênios, obtidos de plantas de girassol colhidas aos 20,60 e 100 DAS, provenientes de lotes de aquênios com distintos níveis de vigor, designados de lote 1, 2 e 3, sob 45.000 e 75.000 sementes hä ${ }^{-1}$.

\begin{tabular}{|c|c|c|c|c|c|c|c|c|c|}
\hline \multirow[b]{2}{*}{ Lotes } & \multicolumn{3}{|c|}{20} & \multicolumn{3}{|c|}{60} & \multicolumn{3}{|c|}{100} \\
\hline & 45.000 & 75.000 & médias & 45.000 & 75.000 & médias & 45.000 & 75.000 & médias \\
\hline & \multicolumn{9}{|c|}{ Caule $\left(\mathrm{kg} \mathrm{ha}^{-1}\right)$} \\
\hline 1 & 0,1 & 0,2 & $0,1 \mathrm{a}$ & 35 & 15 & $25 \mathrm{a}$ & 7 & 6 & $6 a$ \\
\hline 2 & 0,1 & 0,2 & $0,1 \mathrm{a}$ & 52 & 22 & $37 \mathrm{a}$ & 6 & 3 & $5 a$ \\
\hline 3 & 0,1 & 0,1 & $0,1 \mathrm{a}$ & 42 & 22 & $32 \mathrm{a}$ & 5 & 6 & $5 \mathrm{a}$ \\
\hline Médias & $0,1 \mathrm{~A}$ & $0,2 \mathrm{~A}$ & & $43 \mathrm{~A}$ & $20 \mathrm{~B}$ & & $6 \mathrm{~A}$ & $5 \mathrm{~A}$ & \\
\hline \multicolumn{2}{|c|}{ C.V.(\%) parcela } & 24,68 & & 11,74 & & & 27,33 & & \\
\hline \multicolumn{2}{|c|}{ C.V.(\%) subparcela } & 28,88 & & 24,39 & & & 20,52 & & \\
\hline & \multicolumn{9}{|c|}{ Folhas $\left(\mathrm{kg} \mathrm{ha}^{-1}\right)$} \\
\hline 1 & 0,7 & 0,7 & $0,7 \mathrm{a}$ & 50 & 41 & $45 \mathrm{a}$ & 5 & 4 & $4 a$ \\
\hline 2 & 0,8 & 0,8 & $0,8 \mathrm{a}$ & 72 & 55 & $63 \mathrm{a}$ & 4 & 4 & $4 a$ \\
\hline 3 & 0,8 & 0,8 & $0,8 \mathrm{a}$ & 71 & 61 & $66 \mathrm{a}$ & 3 & 4 & $3 a$ \\
\hline Médias & $0,8 \mathrm{~A}$ & $0,8 \mathrm{~A}$ & & $64 \mathrm{~A}$ & $52 \mathrm{~B}$ & & $4 \mathrm{~A}$ & $4 \mathrm{~A}$ & \\
\hline \multicolumn{2}{|c|}{ C.V.(\%) parcela } & 32,40 & & 4,67 & & & 20,99 & & \\
\hline \multicolumn{2}{|c|}{ C.V.(\%) subparcela } & 30,94 & & 13,63 & & & 18,16 & & \\
\hline & \multicolumn{9}{|c|}{ Capítulo $\left(\mathrm{kg} \mathrm{ha}^{-1}\right)$} \\
\hline 1 & - & - & - & 16 & 13 & $14 \mathrm{a}$ & 14 & 14 & $14 \mathrm{a}$ \\
\hline 2 & - & - & - & 20 & 16 & $18 \mathrm{a}$ & 16 & 10 & $13 \mathrm{a}$ \\
\hline 3 & - & - & - & 24 & 18 & $21 \mathrm{a}$ & 12 & 11 & $11 \mathrm{a}$ \\
\hline Médias & - & - & - & $20 \mathrm{~A}$ & $15 \mathrm{~A}$ & & $14 \mathrm{~A}$ & $12 \mathrm{~A}$ & \\
\hline \multicolumn{2}{|c|}{ C.V.(\%) parcela } & & & 21,69 & & & 5,74 & & \\
\hline \multicolumn{4}{|c|}{ C.V.(\%) subparcela } & 15,31 & & & 17,57 & & \\
\hline & \multicolumn{9}{|c|}{ Aquênios $\left(\mathrm{kg} \mathrm{ha}^{-1}\right)$} \\
\hline 1 & - & - & - & - & - & - & 68 & 63 & $66 \mathrm{a}$ \\
\hline 2 & - & - & - & - & - & - & 97 & 66 & $82 \mathrm{a}$ \\
\hline 3 & - & - & - & - & - & - & 106 & 66 & $86 a$ \\
\hline Médias & - & - & - & - & - & - & $88 \mathrm{~A}$ & $65 \mathrm{~A}$ & \\
\hline \multicolumn{4}{|c|}{ C.V.(\%) parcela } & & & & 9,56 & & \\
\hline \multicolumn{4}{|c|}{ C.V.(\%) subparcela } & & & & 11,95 & & \\
\hline & \multicolumn{9}{|c|}{ Total $\left(\mathrm{kg} \mathrm{ha}^{-1}\right)$} \\
\hline 1 & 0,8 & 0,9 & $0,8 \mathrm{a}$ & 101 & 69 & $85 a$ & 94 & 87 & $90 \mathrm{a}$ \\
\hline 2 & 0,9 & 1,0 & $0,9 \mathrm{a}$ & 144 & 93 & $118 \mathrm{a}$ & 123 & 83 & $104 a$ \\
\hline 3 & 0,9 & 0,9 & $0,9 \mathrm{a}$ & 137 & 101 & $119 \mathrm{a}$ & 126 & 87 & $105 \mathrm{a}$ \\
\hline Médias & $0,9 \mathrm{~A}$ & $0,9 \mathrm{~A}$ & & $127 \mathrm{~A}$ & $87 \mathrm{~B}$ & & $112 \mathrm{~A}$ & $86 \mathrm{~A}$ & \\
\hline \multicolumn{2}{|c|}{ C.V.(\%) parcela } & 37,94 & & 2,13 & & & 8,18 & & \\
\hline \multicolumn{2}{|c|}{ C.V.(\%) subparcela } & 37,32 & & 13,86 & & & 9,47 & & \\
\hline & & & & & $\mathrm{IC}$ & & & & \\
\hline 1 & - & - & - & - & - & - & 0,72 & 0,72 & $0,72 \mathrm{a}$ \\
\hline 2 & - & - & - & - & - & - & 0,79 & 0,79 & $0,79 \mathrm{a}$ \\
\hline 3 & - & - & - & - & - & - & 0,84 & 0,76 & $0,80 \mathrm{a}$ \\
\hline Médias & - & - & - & - & - & - & $0,79 \mathrm{~A}$ & $0,76 \mathrm{~A}$ & \\
\hline \multicolumn{4}{|c|}{ C.V.(\%) parcela } & & & & 12,16 & & \\
\hline \multicolumn{4}{|c|}{ C.V.(\%) subparcela } & & & & 7,23 & & \\
\hline
\end{tabular}

Médias seguidas pela mesma letra, maiúscula na linha e minúscula na coluna, não diferem entre si pelo teste Tukey, a 5\%. 
Tabela 3. Dados médios de acúmulo de fósforo no caule, nas folhas, no capítulo, nos aquênios e total, e de índice de colheita dos aquênios obtidos de plantas de girassol colhidas aos 20,60 e 100 dias após a semeadura, provenientes de lotes de aquênios com distintos níveis de vigor, designados de lote 1, 2 e 3, sob 45.000 e 75.000 sementes ha-1. $^{-1}$.

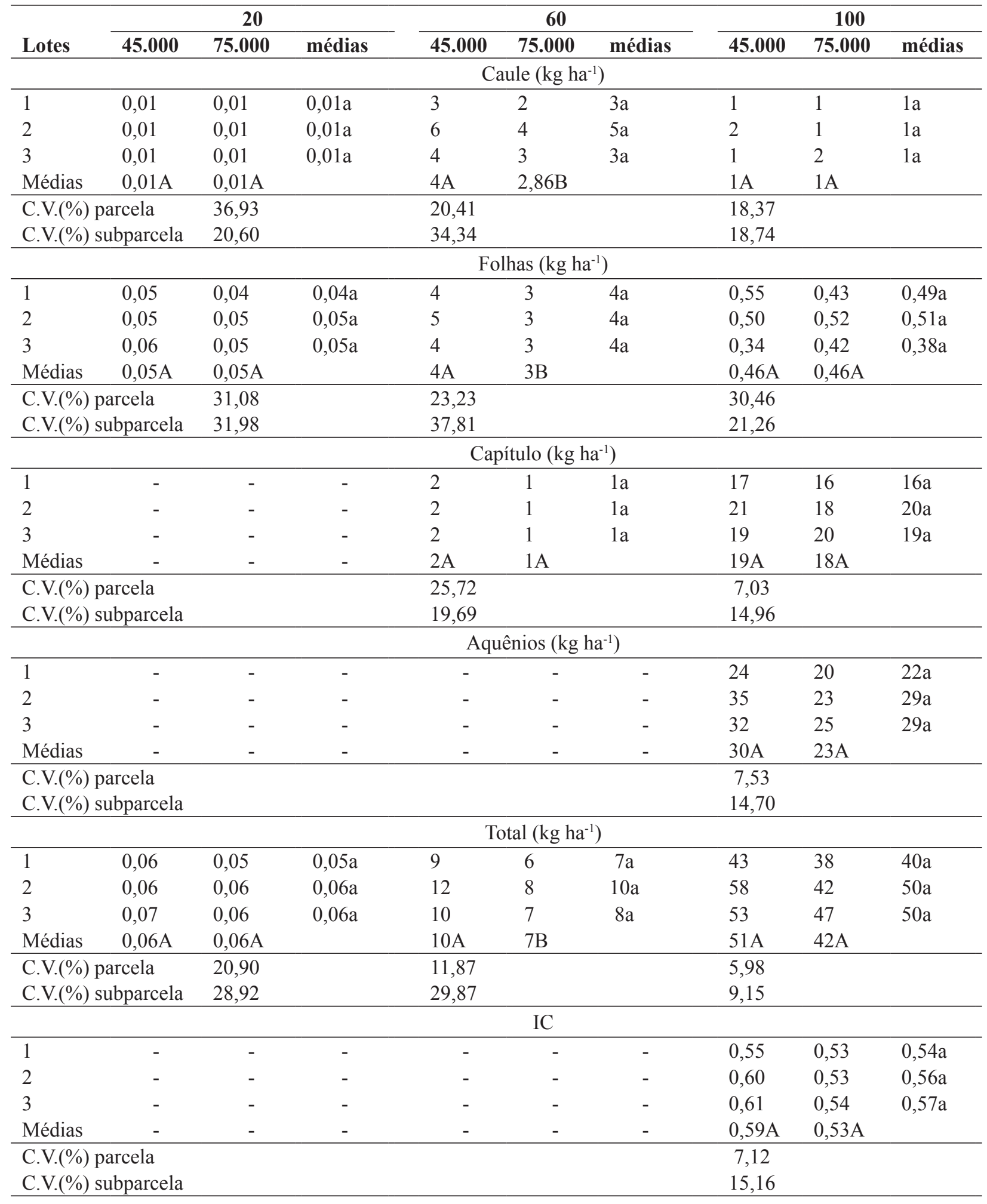

Médias seguidas pela mesma letra, maiúscula na linha e minúscula na coluna, não diferem entre si pelo teste Tukey. 
Tabela 4. Dados médios de acúmulo de potássio no caule, nas folhas, no capítulo, nos aquênios e total, e de índice de colheita dos aquênios obtidos de plantas de girassol colhidas aos 20,60 e 100 dias após a semeadura, provenientes de lotes de aquênios com distintos níveis de vigor, designados de lote 1, 2 e 3, sob 45.000 e 75.000 sementes ha ${ }^{-1}$.

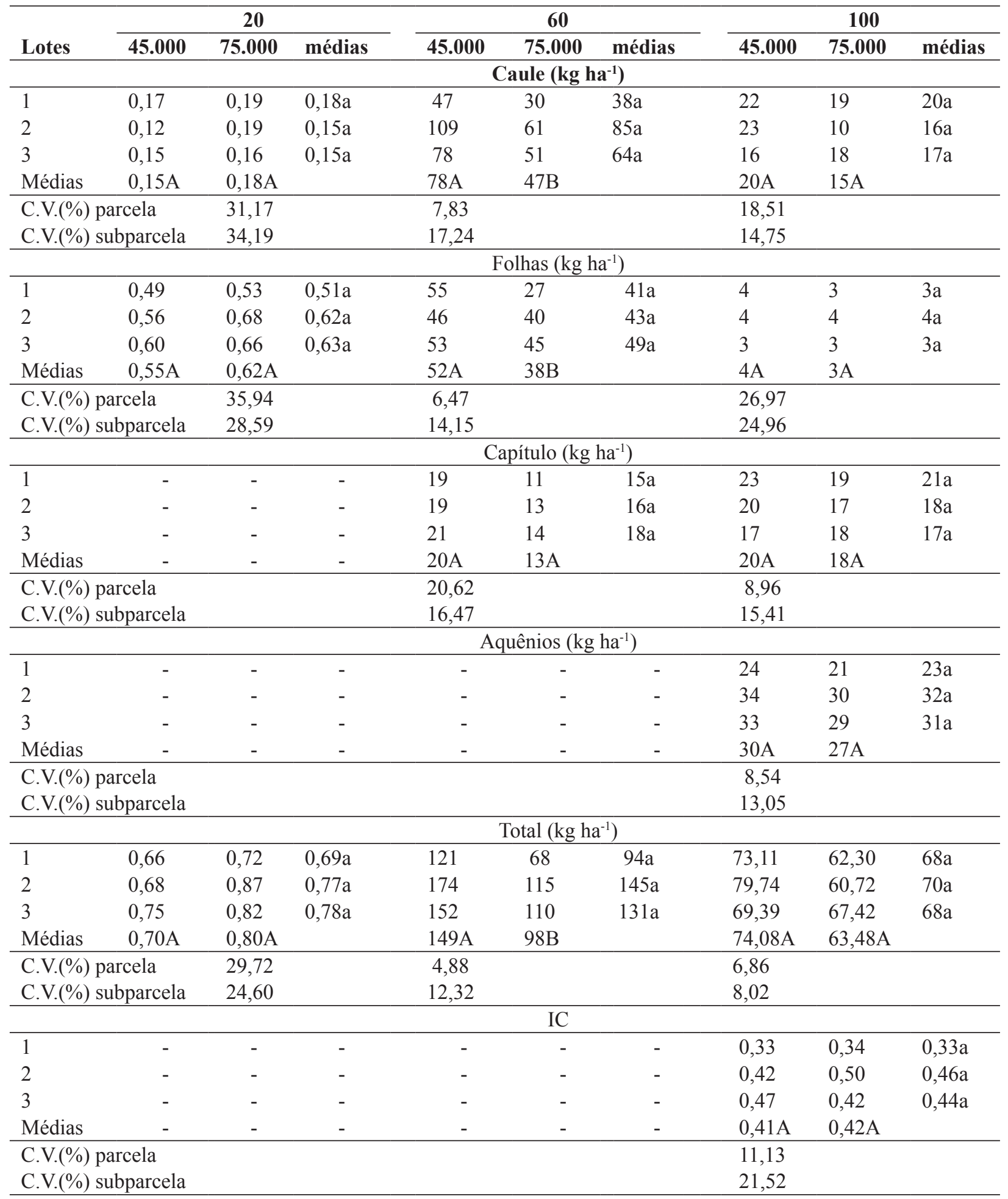

Médias seguidas pela mesma letra, maiúscula na linha e minúscula na coluna, não diferem entre si pelo teste Tukey, a 5\%. 
Pela (Tabela 5), pode-se constatar que, aos 20 DAS, não houve diferença significativa entre as densidades de semeadura e entre lotes de aquênios para acúmulo de Ca no caule, nas folhas e total. No entanto, aos 60 DAS, o maior acúmulo de $\mathrm{Ca}$, no caule, nas folhas e total foi obtido sob a menor densidade de semeadura (45.000 sementes.ha-1), sendo que neste período o acúmulo total foi de 116 $\mathrm{kg} \mathrm{ha}^{-1}$ (Tabela 5). Sfredo, Campo e Sarruge (1984), verificaram que o acúmulo de Ca por plantas de girassol da cultivar Contisol, nesta mesma fase de desenvolvimento, foi de $110 \mathrm{~kg} \mathrm{ha}^{-1}$. Para o índice de colheita de cálcio não foi constatada diferença entre os tratamentos (Tabela 5). Constatou-se que os índices de colheita de nitrogênio (Tabela 2) e de fósforo (Tabela 3 ) foram superiores aos índices de colheita de aquênios (Tabela 1), de potássio (Tabela 4) e de cálcio (Tabela 5), indicando uma translocação preferencial de $\mathrm{N}$ e $\mathrm{P}$ para os aquênios. Nesse aspecto, Castro e Oliveira (2005) relataram que para a cultura do girassol, apenas o N e o P são exportados em grandes quantidades para os aquênios, enquanto os demais nutrientes apresentam taxa de exportação reduzida, ficando as maiores quantidades nos restos vegetais como caule e folhas.

Observou-se que sob a menor densidade de semeadura (45.000 sementes $\mathrm{ha}^{-1}$ ), a maior porcentagem de óleo nos aquênios foi obtido de plantas provenientes do lote 1 , considerado de menor vigor, enquanto que, sob a densidade de 75.000 sementes $\mathrm{ha}^{-1}$, a maior porcentagem foi observada para os lotes 2 e 3 , sendo respectivamente considerados de médio e alto vigor (Tabela 6). Além disso, o teor de óleo dos aquênios foi em média de $48,98 \%$ e $50,66 \%$ quando obtidos nas densidades de semeadura de 45.000 e 75.000 sementes ha1, respectivamente. Silva e Nepomuceno (1991) verificaram que para a cultivar Contisol 711, ao aumentar a densidade de 30.000 para 70.000 sementes $\mathrm{ha}^{-1}$, o teor de óleo aumentou de $42,4 \%$ para $45,6 \%$.

Para o rendimento de aquênios, foi verificado maior valor médio sob a densidade de 45.000 sementes $\mathrm{ha}^{-1}$, independente do vigor dos lotes de aquênios (Tabela 6). No entanto, para rendimento de óleo, não foi constatada diferença entre os tratamentos. Para a cultivar Contisol 711, Silva et al. (1995) relataram que o rendimento de óleo aumentou de $793 \mathrm{~kg} \mathrm{ha}^{-1}$ para $1024 \mathrm{~kg} \mathrm{ha}^{-1}$ ao aumentar a densidade de 30.000 para 70.000 plantas $\mathrm{ha}^{-1}$, já para a cultivar GR 10, o rendimento de óleo reduziu de 1500 para $1200 \mathrm{~kg} \mathrm{ha}^{-1}$ à medida que se elevou a densidade de 30.000 para 80.000 plantas $\mathrm{ha}^{-1}$, principalmente devido ao decréscimo no rendimento de aquênios. 
Tabela 5. Dados médios de acúmulo de cálcio no caule, nas folhas, no capítulo, nos aquênios e total, e de índice de colheita dos aquênios obtidos de plantas de girassol colhidas aos 20,60 e 100 dias após a semeadura, provenientes de lotes de aquênios com distintos níveis de vigor, designados de lote 1, 2 e 3, sob 45.000 e 75.000 sementes ha ${ }^{-1}$.

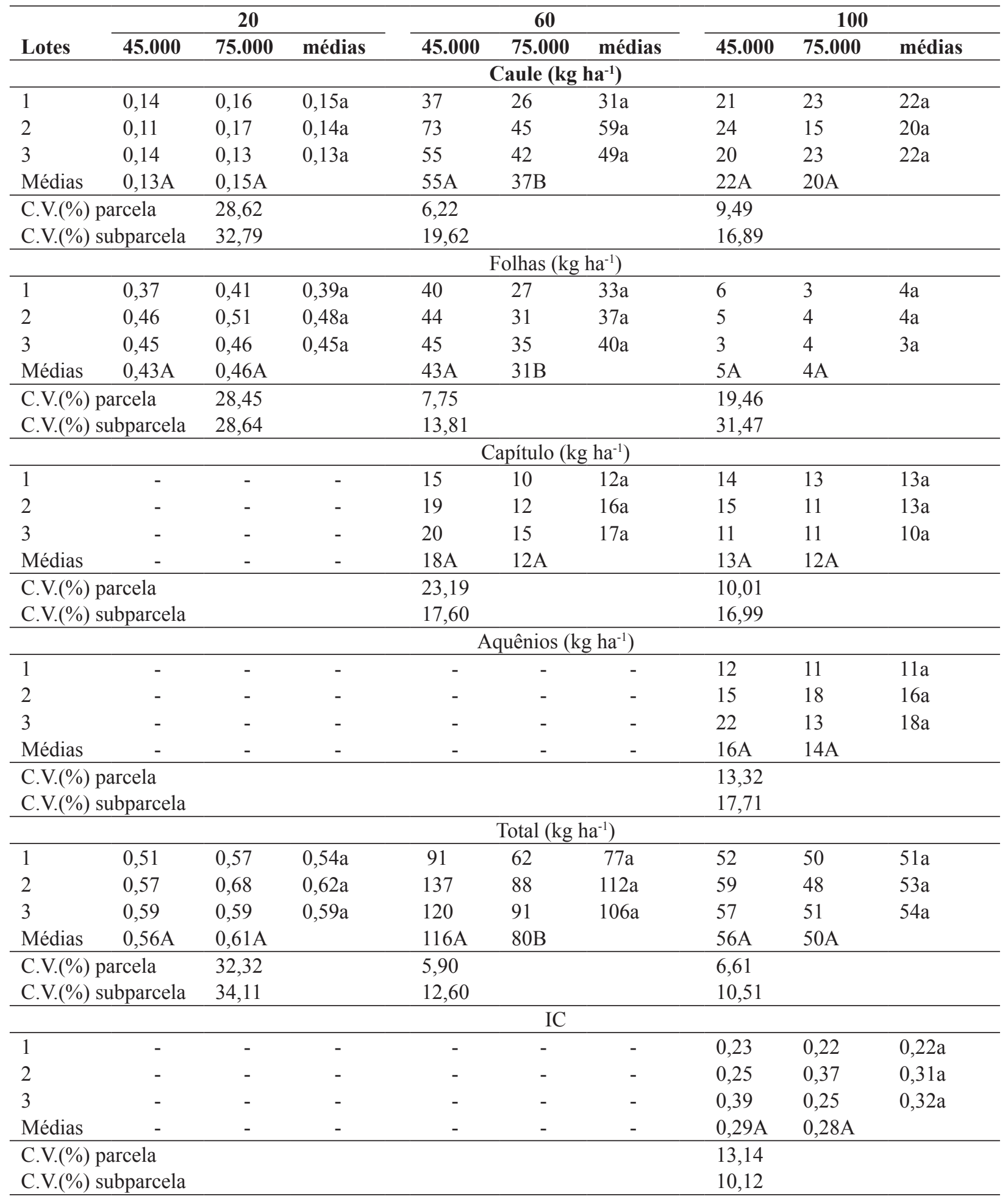

Médias seguidas pela mesma letra, maiúscula na linha e minúscula na coluna, não diferem entre si pelo teste Tukey, a 5\%. 
Tabela 6. Dados médios de teor de óleo dos aquênios (\%) e de rendimento de aquênios e de óleo $\left(\mathrm{kg} \cdot \mathrm{ha}^{-1}\right)$ obtidas de plantas de girassol provenientes de lotes de aquênios com distintos níveis de vigor, designados de lote 1, 2 e 3, sob 45.000 e 75.000 sementes $^{-1}{ }^{-1}$.

\begin{tabular}{|c|c|c|c|}
\hline Lotes & 45.000 & 75.000 & Médias \\
\hline \multicolumn{4}{|c|}{ Teor de óleo (\%) } \\
\hline 1 & 49,96Аa & $48,99 \mathrm{Bb}$ & 49,48 \\
\hline 2 & $49,38 \mathrm{Bb}$ & $51,01 \mathrm{Aa}$ & 50,19 \\
\hline 3 & $47,62 \mathrm{Bc}$ & $51,98 \mathrm{Aa}$ & 49,80 \\
\hline Médias & 48,98 & 50,66 & \\
\hline C.V.(\%) parcela & 0,41 & & \\
\hline C.V.(\%) subparcela & 0,71 & & \\
\hline \multicolumn{4}{|c|}{ Rendimento de aquênios $\left(\mathrm{kg} \mathrm{ha}^{-1}\right)$} \\
\hline 1 & 1242,88 & 1287,62 & $1265,25 \mathrm{a}$ \\
\hline 2 & 1587,39 & 1365,40 & $1476,39 a$ \\
\hline 3 & 2000,35 & 1139,81 & $1570,08 \mathrm{a}$ \\
\hline Médias & $1610,21 \mathrm{~A}$ & $1264,27 \mathrm{~B}$ & \\
\hline C.V.(\%) parcela & 6,25 & & \\
\hline C.V.(\%) subparcela & 10,13 & & \\
\hline \multicolumn{4}{|c|}{ Rendimento de óleo $\left(\mathrm{kg} \mathrm{ha}^{-1}\right)$} \\
\hline 1 & 620,94 & 630,80 & $625,87 \mathrm{a}$ \\
\hline 2 & 783,85 & 696,49 & $740,14 \mathrm{a}$ \\
\hline 3 & 952,57 & 592,47 & $772,52 \mathrm{a}$ \\
\hline Médias & $785,78 \mathrm{~A}$ & $639,92^{\mathrm{a}}$ & \\
\hline C.V.(\%) parcela & 12,61 & & \\
\hline C.V.(\%) subparcela & 8,94 & & \\
\hline
\end{tabular}

Médias seguidas pela mesma letra, maiúscula na linha e minúscula na coluna, não diferem entre si pelo teste Tukey, a 5\%.

\section{Conclusões}

Aos 60 DAS, entre o florescimento e o enchimento, ocorreu maior acúmulo de massa de matéria seca e de N, P, K e Ca no caule, nas folhas e total nas plantas de girassol produzidas sob a menor densidade de 45.000 sementes ha $^{-1}$. Não houve efeito do vigor dos aquênios e da densidade de semeadura no rendimento de óleo dos aquênios de girassol e nos índices de colheita de aquênios e nutrientes. Houve translocação preferencial de $\mathrm{N}$ e P para os aquênios.

\section{Referências}

BANZATTO, D. A.; KRONKA, S. N. Experimentação agrícola. 4. ed. Jaboticabal: Funep, 2006. 237 p.

CARVALHO, C. G. P.; OLIVEIRA,A.C.B.; MARQUES, C. R. G.; SALASAR, F. P. L. T.; PANDOLFI, T. J. F.;
CAMPOS, R.; FAGUNDES, R. A. Informes da avaliação de genótipos de girassol 2005/2006 e 2006. Londrina: CNPSo, 2007, $120 \mathrm{p}$.

CASTRO, C.; FARIAS, J. R. B. Ecofisiologia do girassol. In: LEITE, R. M. V. B. de C.; BRIGHENTI, A. M.; CASTRO, C. (Ed.). Girassol no Brasil. Londrina: Embrapa Soja, 2005. p. 163-218.

CASTRO, C.; OLIVEIRA, F. A. Nutrição e adubação do girassol. In: LEITE, R. M. V. B. de C.; BRIGHENTI, A. M.; CASTRO, C. (Ed.). Girassol no Brasil. Londrina: Embrapa Soja, 2005. p. 317-373.

COX, W. J.; JOLLIFF, G. D. Growth and yield of sunflower and soybean under soil water deficits. Agronomy Journal, Madison, v. 78, n. 1, p. 226-230, 1986.

ESTADOS UNIDOS. Departament of Agriculture. Foreign Agricultural Service. Oilseeds: world markets and trade. Washington, 2008. 34 p. (Circular Series, FOP 2-08). 
LAZZAROTTO, J. J.; ROESSING, A. C.; MELLO, A. C. Agronegócio do girassol no mundo e no Brasil. In: LEITE, R. M.V. B. C.; BRIGHENTI, A. M.; CASTRO, C. (Ed.). Girassol no Brasil. Londrina: Embrapa Soja, 2005. p. 15-42.

MALAVOLTA, E.; VITTI, G. C.; OLIVEIRA, S. A. Avaliação do estado nutricional das plantas: princípios e aplicações. Piracicaba: Associação Brasileira para Pesquisa da Potasa e do Fosfato, 1997. 319 p.

MURCIA, M.; PERETTI, A.; MARTINO, S. S.; PEREYRA, V. Vigor de semillas y emergência a campo de girassol (Helianthus annus L.) em siembras anticipadas em el sudeste de la província de Buenos Aires (Argentina). Revista Brasileira de Sementes, Brasília, v. 23, n. 2, p. 263-267, 2001.

MUSSI, M. M. Germinação e vigor de sementes de girassol (Helianthus annuus L.) submetidas a diferentes concentrações de $\mathrm{CO}_{2}$, períodos de exposição e embalagens. 2005. Dissertação(Mestrado em Agronomia) - Departamento de Fitotecnia e Fitossanitarismo. Universidade Federal do Paraná, Curitiba.

OLIVEIRA, F. A.; CASTRO, C.; FRANCHINI, J. C.; TORRES, E. Manejo do solo. In: LEITE, R. M. V. B. C.; BRIGHENTI, A. M.; CASTRO, C. (Ed.). Girassol no Brasil. Londrina: Embrapa Soja, 2005. p. 299-316.

PORTO, W. S.; CARVALHO, C. G. P.; PINTO, R. J. B.; OLIVEIRA, M. F.; OLIVEIRA, A. C. B. Evaluation of sunflower cultivars for Central Brazil. Scientia Agrícola, Piracicaba, v. 65, n. 2, p. 139-144, 2008.

RAIJ, B. V.; CANTARELLA, H.; FURLANI, A. M. C. Recomendações de adubação e calagem para o Estado de São Paulo. 2 ed. Campinas: Instituto Agronômico/ Fundação IAC, 1997198 p.

RIBEIRO JÚNIOR, J. I. Análises estatísticas no SAEG. 19. ed. Viçosa, MG: UFV, 2001. 301 p.

RIZZARDI, M. A.; SILVA, P. R. F. Partição de matéria seca e óleo nos aquênios de girassol em função da densidade de plantas. Revista Brasileira de Fisiologia Vegetal, Brasília, v. 4, n. 2, p. 113-116, 1992.

SCHNEITER, A. A.; MILLER, J. F. Description of sunflower growth stages. Crop Science, Madison, v. 21, n. 6, p. 901-903, 1981.

SFREDO, G. J.; CAMPO, R. J.; SARRUGE, J. R. Girassol: nutrição mineral e adubação. Londrina: Embrapa-CNPSo, 1984. 36 p.

SILVA, P. P. R.; NEPOMUCENO, A. L. Efeito do arranjo de plantas no rendimento de grãos., componentes de rendimento, teor de óleo e no controle de plantas daninhas em girassol. Pesquisa Agropecuária Brasileira, Brasília, v. 26, n. 9, p. 1503-1508, 1991.

SILVA, P. R. P.; RIZZARDI, M. A.; TREZZI, M. M.; ALMEIDA, M. L. de. Densidade e arranjo de plantas em girassol. Pesquisa Agropecuária Brasileira, Brasília, v. 30, n. 6, p. 797-810, 1995.

TEDESCO, M. J. Análise de solo, plantas e outros materiais. Porto Alegre: UFRGS, 1995. 174 p.

UNGARO, M. R. G.; TOLEDO, N. M. P.; TEIXEIRA, J. P. F.; SUASSUNA FILHO, J. Determinação do teor de óleo em sementes de girassol pelos métodos de ressonância magnética nuclear e "soxhlet". Bragantia, Campinas, v. 51, n. 1, p. 1-5, 1992. 